\title{
Involvement of nucleoside diphosphate kinase $b$ and elongation factor 2 in Leishmania braziliensis antimony resistance phenotype
}

\author{
Douglas S. Moreira and Silvane M. F. Murta
}

\begin{abstract}
Background: Nucleoside diphosphate kinase b (NDKb) is responsible for nucleoside triphosphates synthesis and it has key role in the purine metabolism in trypanosomatid protozoans. Elongation factor 2 (EF2) is an important factor for protein synthesis. Recently, our phosphoproteomic analysis demonstrated that NDKb and EF2 proteins were phosphorylated and dephosphorylated in antimony (Sb $\left.{ }^{\prime \prime \prime}\right)$-resistant L. braziliensis line compared to its Sb ${ }^{\text {III }}$ susceptible pair, respectively.
\end{abstract}

Methods: In this study, the overexpression of NDKb and EF2 genes in L. braziliensis and L. infantum was performed

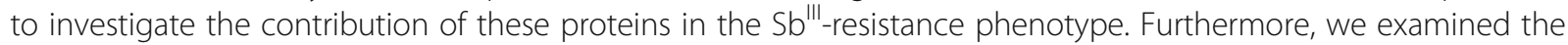
role of lamivudine on Sb' $\mathrm{III}^{\mathrm{I}}$ susceptibility in clones that overexpress the NDKb gene, and the effect of EF2 kinase (EF2K) inhibitor on the growth of EF2-overexpressing parasites.

Results: Western blot analysis demonstrated that NDKb and EF2 proteins are more and less expressed, respectively, in Sb'II-resistant line of L. braziliensis than its wild-type (WTS) counterpart, corroborating our previous phosphoproteomic data. NDKb or EF2-overexpressing L. braziliensis lines were 1.6 to 2.1 -fold more resistant to Sb ${ }^{\text {III }}$ than the untransfected WTS line. In contrast, no difference in Sb ${ }^{\text {III }}$ susceptibility was observed in L. infantum parasites overexpressing NDKb or EF2. Susceptibility assays showed that NDKb-overexpressing L. braziliensis lines presented elevated resistance to lamivudine, an antiviral agent, but it did not alter the leishmanicidal activity in

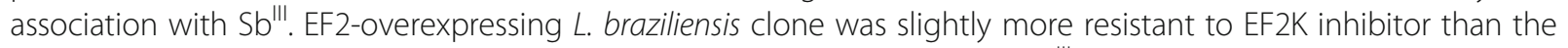
WTS line. Surprisingly, this inhibitor increased the antileishmanial effect of Sb"l', suggesting that this association might be a valuable strategy for leishmaniasis chemotherapy.

Conclusion: Our findings represent the first study of NDKb and EF2 genes overexpression that demonstrates an increase of Sb ${ }^{\text {III }}$ resistance in L. braziliensis which can contribute to develop new strategies for leishmaniasis treatment.

Keywords: Leishmania spp., Nucleoside diphosphate kinase b, Elongation factor 2, Chemotherapy, Antimony resistance

\footnotetext{
* Correspondence: silvane@cpqrr.fiocruz.br

Centro de Pesquisas René Rachou CPqRR, Fundação Oswaldo Cruz -

FIOCRUZ, Avenida Augusto de Lima 1715, Belo Horizonte, MG, Brazil
} 


\section{Background}

Leishmaniasis refers to a disease complex caused by protozoan Leishmania parasites which are transmitted to humans by the bite of infected female phlebotomine sandflies. According to the World Health Organization (WHO), leishmaniasis is a neglected tropical disease that constitutes a public health problem in many developing countries of the Indian subcontinent, Latin America and East Africa [1]. Human leishmaniasis has an incidence of 1.2 million new cases annually, with an estimated population of 350 million at risk and a prevalence of 12 million cases [2]. Depending on genetic and environmental factors, the host immune response and mainly on Leishmania species involved, the disease can comprise three main clinical manifestations: cutaneous (CL), mucocutaneous (MCL) or visceral (VL) [3]. In the New World, $L$. (Viannia) braziliensis is the causative agent of CL and MCL, whereas L. (Leishmania) infantum [syn. L. (L.) chagasi] causes VL, which is lethal if not treated [4, 5].

Pentavalent antimonials $\left(\mathrm{Sb}^{\mathrm{V}}\right)$, such as sodium stibogluconate (Pentostam ${ }^{\odot}$ ) and meglumine antimoniate (Glucantime $^{\circledast}$ ), remain the first-line of treatment against all forms of the disease for more than 70 years especially in developing countries [6]. Despite the mechanism of antimony action has not been completely elucidated, studies suggest that $\mathrm{Sb}^{\mathrm{V}}$ is reduced to trivalent form $\left(\mathrm{Sb}^{\mathrm{III}}\right)$ that is active against amastigote and promastigote forms of Leishmania [7]. Earlier reports have indicated that antimonials inhibit fatty acid $\beta$-oxidation and glycolysis [8], and cause perturbations in the thiol redox potential, which would drive to parasite death by oxidative stress [9]. Furthermore, it has been suggested that antimony can kill the parasite by an apoptosis process resulting in DNA fragmentation and externalization of phosphatidylserine outside of Leishmania [10, 11].

The emergence and spread of resistance to antimony is significant in determined regions, such as Bihar state in India where over $60 \%$ of VL patients do not respond to the traditional therapy using antimonials [12]. Recent studies have demonstrated several mechanisms in Leishmania species implicated in resistance to these compounds. Thus, antimony resistance constitutes a multifactorial process and involves at least some of following aspects. A decrease in rate of reduction from pentavalent to trivalent form or loss of reductase activity may lead to drug resistance [13, 14]. Lower expression of AQP1 (aquaglyceroporin), which is involved in $\mathrm{Sb}^{\mathrm{III}}$ uptake into parasite, was also observed in resistant mutants $[15,16]$. Increased levels of intracellular thiols were found in cells selected for resistance to $\mathrm{Sb}^{\mathrm{III}}$ [17] as well as in unresponsive clinical isolates [18-20]. MRPA (multidrug resistance associated protein A) transporter confers resistance by sequestering thiol-Sb conjugates into an intracellular vacuole which removes the drug from the cytoplasm of the parasite [21]. An increase of PGP (phosphoglycoprotein) expression was described in Leishmania resistant to antimonials [22], suggesting that this protein mediates the efflux of these drugs from the parasite. Moreover, other mechanisms can also contribute to the antimony resistance phenotype in Leishmania.

Nucleoside diphosphate kinase b (NDKb), a NDK family member, is ubiquitous enzyme that is crucial to transfer phosphate group from a nucleoside triphosphate (NTP) to a nucleoside diphosphate (NDP), using a pingpong mechanism that involves a phosphohistidine intermediate $[23,24]$. The whole reaction is described as follows [25]:

$$
\begin{aligned}
\mathrm{NDK} & +\mathrm{N}_{1} \mathrm{TP} \leftrightarrow \mathrm{NDK}-\mathrm{P}+\mathrm{N}_{1} \mathrm{DP} \leftrightarrow \mathrm{NDK}-\mathrm{P} \\
& +\mathrm{N}_{2} \mathrm{DP} \leftrightarrow \mathrm{NDK}+\mathrm{N}_{2} \mathrm{TP}
\end{aligned}
$$

NDKs play pivotal roles in different organisms, such as in bacterial pathogenesis [26], regulation of gene expression in cells of mammals [27] and participation in the purine salvage pathways of protozoan parasites [28]. NTP is a precursor for DNA and RNA synthesis, evidencing that NDK is also an essential enzyme for all cellular processes involving nucleic acids in distinct species of organisms [24]. Unlike mammals, Leishmania is not able to synthesize purines by means of a de novo mechanism and thus depend upon the host for survival [29]. Kolli et al. [30] showed that Leishmania-released NDK avoids ATP-mediated lysis of macrophages, keeping the integrity of host cells to the advantage of the parasite. Therefore, NDKb can be considered an interesting target for drug discovery for chemotherapy of leishmaniasis.

The regulation of protein synthesis in eukaryotic cells occurs via both initiation and elongation levels. This process uses significant quantity of cellular energy, and the vast majority of this is consumed in elongation [31]. Elongation factor 2 (EF2) codifies a member of the GTPbinding translation elongation factor family and it is a relevant factor for production of proteins. EF2, which is a ubiquitous enzyme, makes the GTP-dependent translocation of the aminoacyl-tRNA from the A-site to the P-site of the ribosome [32]. EF2 protein was found with increased abundance in promastigote forms of $L$. panamensis resistant to $\mathrm{Sb}^{\mathrm{III}}$ [33].

Considering the multiplicity of antimony resistance mechanisms, our knowledge about them in New World Leishmania species is far from being fully elucidated. Recently, our phosphoproteomic analysis demonstrated that the nucleoside diphosphate kinase b (NDKb) and elongation factor 2 (EF2) proteins were phosphorylated and dephosphorylated, respectively, in $\mathrm{Sb}^{\mathrm{III}}$-resistant $L$. braziliensis line compared to its wild-type (WTS) counterpart [34]. In this study, $N D K b$ and EF2 genes were transfected in $\mathrm{Sb}^{\mathrm{III}}$-susceptible lines of L. braziliensis and 
L. infantum to determine whether the overexpression of these proteins contributes to antimony resistance phenotype in these parasites. Moreover, we investigated the role of lamivudine on $\mathrm{Sb}^{\mathrm{III}}$ susceptibility in NDKboverexpressing clones, and the effect of EF2 kinase (EF2K) inhibitor on the growth of EF2-overexpressing parasites.

\section{Methods}

\section{Leishmania spp. cultures}

We used promastigote forms of L. braziliensis (MHOM/ BR/75/M2904) and L. infantum (MHOM/BR/74/PP75) in our study. The antimony-resistant lines were previously selected in vitro to potassium antimonyl tartrate $\left(\mathrm{Sb}^{\mathrm{III}}\right)\left(\mathrm{C}_{8} \mathrm{H}_{4} \mathrm{~K}_{2} \mathrm{O}_{12} \mathrm{Sb}_{2} \cdot 3 \mathrm{H}_{2} \mathrm{O}\right)$ by step-wise drug pressure and their resistance indices were 20-fold and 4-fold higher than those of their wild-type counterparts, respectively [35]. Parasites were grown at $26{ }^{\circ} \mathrm{C}$ in M199 medium supplemented with $2 \mathrm{mM}$ L-glutamine, $5 \mu \mathrm{g} / \mathrm{ml}$ hemin, $50 \mu \mathrm{g} / \mathrm{ml}$ streptomycin, $2 \mu \mathrm{g} / \mathrm{ml}$ biopterin, $1 \mu \mathrm{g} /$ $\mathrm{ml}$ biotin, $40 \mathrm{mM}$ HEPES $\mathrm{pH}$ 7.4, $500 \mathrm{U}$ penicillin and $10 \% \mathrm{v} / \mathrm{v}$ heat-inactivated fetal calf serum [35]. These parasites were harvested in the logarithmic growth phase to perform all analyses.

\section{Generation of NDKb and EF2 overexpressing lines}

A 456 bp fragment corresponding to $N D K b$ encoding region (TriTrypDB accession number LbrM.32.3210) was amplified with $P f x$ DNA polymerase (Invitrogen) from $L$. braziliensis genomic DNA using the forward primer: $5^{\prime}$-TGG ATC CCC ACC ATG TCC TCC GAG CGC ACT TT-3' and the reverse primer: 5' $-\mathrm{TTG}$ GAT CCC TAT TCG TAG ATC TGG CAA GCG G-3'. Other 2,538 bp fragment corresponding to EF2 encoding region (TriTrypDB accession number LbrM.35.0270) was also amplified with the enzyme cited above using $L$. braziliensis genomic DNA and the primers forward: 5'TGG ATC CCC ACC ATG GTG AAC TTT ACC GTC GAT CAG-3' and reverse: 5'-TTG GAT CCT TAC AAT TTA TCC ATG AAC TGG TCC A-3'. The underlined sequences correspond to BamHI restriction site. The obtained PCR products were cloned into the pGEM-T Easy ${ }^{\odot}$ vector (Promega, Madison, WI, USA) and subsequently submitted to sequencing reaction for confirmation of correct sequence. All constructs were sequenced in an ABI 3130 (Applied Biosystems, Foster City, CA, USA). The pGEM-NDKb and pGEM-EF2 constructs were restricted with $B a m \mathrm{HI}$ and the fragments released were subcloned into the dephosphorylated PIR1BSD expression vector (kindly provided by Dr. Stephen Beverley, Washington University, USA). To confirm the correct direction of cloning, the constructs were then digested with HindIII and SmaI releasing fragments that confirmed the sense direction of the genes
$N D K b$ and EF2, respectively. Thus, the constructs pIR1BSD (empty vector), pIR1BSD-NDKb and pIR1BSD-EF2 were linearized by SwaI digestion and electroporated into wild-type L. braziliensis and L. infantum lines using a GenePulser XCell electroporation system (Bio-Rad, Hercules, CA, USA). This allowed integration of the vector into the $18 \mathrm{~S}$ ribosomal DNA small subunit locus [36]. Colonies were obtained following plating on semisolid M199 medium containing blasticidin (BSD) $(10 \mu \mathrm{g} / \mathrm{ml})$. After $1-2$ weeks, clonal lines were selected and the presence of constructs was confirmed by PCR tests using genomic DNA with primers specific for the BSD marker.

\section{Protein levels}

Western blot assays were carried out for investigating the expression level of NDKb and EF2 proteins in the transfected parasites and in the $\mathrm{Sb}^{\mathrm{III}}$-resistant and -susceptible lines of L. braziliensis and L. infantum. Total proteins from these parasites were extracted according to the protocol previously described [37]. Subsequently, $20 \mu \mathrm{g}$ from each sample were separated by electrophoresis on $12 \%$ SDS-polyacrylamide gel and transferred onto nitrocellulose membranes (Bio-Rad, Hercules, CA, USA). They were blocked, washed and probed with rabbit polyclonal anti-NDKb (1:200) (Abcam, Cambridge, UK, \#ab154274) or rabbit monoclonal anti-EF2 (1:200) (Abcam, Cambridge, UK, \#ab75748) antibodies, during $12 \mathrm{~h}$ at $4{ }^{\circ} \mathrm{C}$ in the blocking solution. According to manufacturer specifications, the immunogen of the first antibody is a recombinant fragment corresponding to a region within amino acids 1-105 of human NDKb, while the immunogen of the second antibody is a synthetic peptide corresponding to residues on the $\mathrm{C}$ terminal of human EF2 (Abcam, Cambridge, UK). The blots were washed twice and incubated with horseradish peroxidase-conjugated anti-rabbit IgG (1:5,000) (GE Healthcare) for $1 \mathrm{~h}$ at room temperature. After incubation, the membranes were washed, incubated with ECL Plus chemiluminescent substrate (GE Healthcare) and revealed by ImageQuant LAS 4000 (GE Healthcare). To confirm equivalent loading, SDS-PAGE containing the samples were stained with Coomassie blue. Furthermore, the blots were normalized using the antibody monoclonal anti- $\alpha$-tubulin $(1: 15,000)$ (Sigma, St. Louis, USA). The intensity of the bands was analyzed using the software GelAnalyzer 2010 (gelanalyzer.com).

\section{Susceptibility assays of Leishmania spp. clonal lines to $\mathrm{Sb}^{\text {III }}$ and $\mathrm{H}_{2} \mathrm{O}_{2}$}

Promastigotes of wild-type L. braziliensis and L. infantum clonal lines non-transfected or transfected with the constructs pIR1BSD (empty vector), pIR1BSD-NDKb or pIR1BSD-EF2 were submitted to $\mathrm{Sb}^{\mathrm{III}}$ (Sigma-Aldrich, 
St. Louis, MO, USA) susceptibility tests. The susceptibility to hydrogen peroxide $\left(\mathrm{H}_{2} \mathrm{O}_{2}\right)$ was also evaluated in the parasites transfected with the $N D K b$ gene. Parasites were incubated in M199 medium at $2 \times 10^{6}$ cells $/ \mathrm{ml}$ into 24-well plates in the absence or presence of several concentrations of $\mathrm{Sb}^{\mathrm{III}}$ (1.17 to $599.04 \mu \mathrm{M}$ which corresponds to 0.00078125 to $0.4 \mathrm{mg} / \mathrm{ml}$ ) or $\mathrm{H}_{2} \mathrm{O}_{2}$ (100 to $350 \mu \mathrm{M})$ for $48 \mathrm{~h}$. The effective concentration required to decrease growth by $50 \%\left(\mathrm{EC}_{50}\right)$ was determined using a model Z1 Coulter Counter (Beckman Coulter, Fullerton, CA, USA). $\mathrm{EC}_{50}$ values were determined from at least three independent measurements performed in triplicate, using the linear interpolation method [38].

\section{Susceptibility assays of $L$. braziliensis lines to lamivudine and EF2K inhibitor and competition assays}

We determined the susceptibility of $L$. braziliensis lines to lamivudine $\left(2^{\prime}, 3^{\prime}\right.$-dideoxy-3' -thiacytidine - $\left.\mathrm{C}_{8} \mathrm{H}_{11} \mathrm{~N}_{3} \mathrm{O}_{3} \mathrm{~S}\right)$ (Globe Química) (kindly provided by Dr. Juliana Medeiros and Dr. Ana Cláudia Tavares, Farmanguinhos/FIOCRUZ, Brazil) and 7-Amino-1-cyclopropyl-3-ethyl-1,2,3,4-tetrahydro-2,4-dioxopyrido [2,3- $d$ ] pyrimidine-6-carboxamide $\left(\mathrm{C}_{13} \mathrm{H}_{15} \mathrm{~N}_{5} \mathrm{O}_{3}\right)$ (Tocris Bioscience, A484954) which are inhibitors for the enzymes $\mathrm{NDKb}$ and elongation factor 2 kinase (EF2K), respectively. $\mathrm{EC}_{50}$ of these inhibitors for wild-type $L$. braziliensis line and parasites that overexpress the $N D K b$ or EF2 genes was determined to be used in competition tests with $\mathrm{Sb}^{\mathrm{III}}$. The cultures $\left(2 \times 10^{6}\right.$ cells/ $\mathrm{ml}$ ) were incubated in the absence or presence of various concentrations of lamivudine $(125$ to $10,000 \mu \mathrm{M})$ or EF2K inhibitor (50 to $300 \mu \mathrm{M}$ ) into 24-well plates during $48 \mathrm{~h}$. After, the percentage of relative growth was determined by automated cell counting. Competition assays were performed to investigate the leishmanicidal activity of the inhibitors cited above in association with $\mathrm{Sb}^{\mathrm{III}}$. In these experiments, $2 \times 10^{6}$ parasites $/ \mathrm{ml}$ were seeded into 24 -well cell culture plates containing medium M199. Subsequently, the $\mathrm{EC}_{50}$ of lamivudine and $\mathrm{EF} 2 \mathrm{~K}$ inhibitor were added concomitantly with $\mathrm{Sb}^{\mathrm{III}} \mathrm{EC}_{50}$ (Table 1), followed by incubation for $48 \mathrm{~h}$. The percentage of relative growth was determined by automated cell counting using a Z1 Coulter Counter.

\section{Statistical analysis}

Data were analyzed by Student's $t$-test performed using the software GraphPad Prism 5.0. A P-value less than 0.05 was considered statistically significant.

\section{Results \\ Expression levels of NDKb and EF2 proteins in Leishmania lines}

We determined the expression levels of the proteins $\mathrm{NDKb}$ and EF2 in the antimony-susceptible and antimony-resistant $L$. braziliensis and $L$. infantum lines by Western blot analysis using polyclonal anti-NDKb and monoclonal anti-EF2 antibodies, respectively. These antibodies are specific for mammalian proteins. It is important to highlight that the identity between the NDKb and EF2 amino acid sequences of $L$. braziliensis compared to mammalian was 66 and $61 \%$, respectively (data not shown). Western blot results revealed that these antibodies recognized polypeptides of $17 \mathrm{kDa}$ and $94 \mathrm{kDa}$ in all Leishmania samples analyzed which correspond to the expected size of NDKb and EF2 proteins, respectively (Fig. 1a). The membranes were incubated with the monoclonal anti- $\alpha$-tubulin antibody for normalization of the results (Fig. 1a). The expression level of NDKb protein was 1.5-fold and 2.4-fold higher in the $\mathrm{Sb}^{\mathrm{III}}$-resistant Leishmania spp. lines (LbSbR and LiSbR) in comparison with their respective wild-type lines (LbWTS and LiWTS) (Fig. 1a). Regarding expression level of EF2 protein, the results demonstrated that this protein was approximately 3 -fold lower in the $\mathrm{Sb}^{\mathrm{III}}$ resistant $L$. braziliensis line when compared to its wildtype counterpart LbWTS. On the other hand, the EF2

Table 1 EC 50 of Sb ${ }^{\prime \prime \prime}$, lamivudine, EF2K inhibitor and hydrogen peroxide and corresponding RI for WTS, NDKb- or EF2-overexpressing L. braziliensis lines. $\mathrm{EC}_{50}$ represents effective concentration required to decrease growth by $50 \%$. The values were determined from at least three independent experiments performed in triplicate, using the linear interpolation method [38]

\begin{tabular}{|c|c|c|c|c|c|c|c|c|}
\hline \multirow[t]{2}{*}{ Parasites } & \multicolumn{2}{|l|}{$S b^{I I I}$} & \multicolumn{2}{|c|}{ Lamivudine } & \multicolumn{2}{|c|}{ EF2K inhibitor } & \multicolumn{2}{|c|}{ Hydrogen peroxide } \\
\hline & $\overline{E C_{50}(\mu M)}$ & $\mathrm{Rl}$ & $\overline{E C_{50}(\mu M)}$ & $\mathrm{Rl}$ & $\overline{E C_{50}}(\mu \mathrm{M})$ & $\mathrm{Rl}$ & $\mathrm{EC}_{50}(\mu \mathrm{M})$ & $\mathrm{RI}$ \\
\hline LbWTS & 7 & - & 766 & - & 173 & - & 213 & - \\
\hline LbplR1BSD & 8 & - & 733 & - & - & - & 207 & - \\
\hline LbNDKb clone 4 & 12 & 1.7 & 2,110 & 2.8 & - & - & 207 & 1.0 \\
\hline LbNDKb clone 9 & 15 & 2.1 & 2,014 & 2.6 & - & - & 207 & 1.0 \\
\hline LbEF2 clone 9 & 14 & 2.0 & - & - & 211 & 1.2 & - & - \\
\hline LbEF2 clone 12 & 11 & 1.6 & - & - & - & - & - & - \\
\hline
\end{tabular}

Chemical formulae and abbreviations: $\mathrm{Sb}^{\text {III }}$ (potassium antimonyl tartrate); lamivudine $\left(\mathrm{C}_{8} \mathrm{H}_{11} \mathrm{~N}_{3} \mathrm{O}_{3} \mathrm{~S}\right)$; EF2 $\mathrm{K}$ inhibitor $\left(\mathrm{C}_{13} \mathrm{H}_{15} \mathrm{~N}_{5} \mathrm{O}_{3}\right)$; hydrogen peroxide $\left(\mathrm{H}_{2} \mathrm{O}_{2}\right) ;$ WTS wild-type susceptible, $L b L$. (V.) braziliensis, pIR1BSD expression vector, NDKb nucleoside diphosphate kinase b, EF2 elongation factor 2 , EF2K elongation factor 2 kinase, $R /$ resistance index 

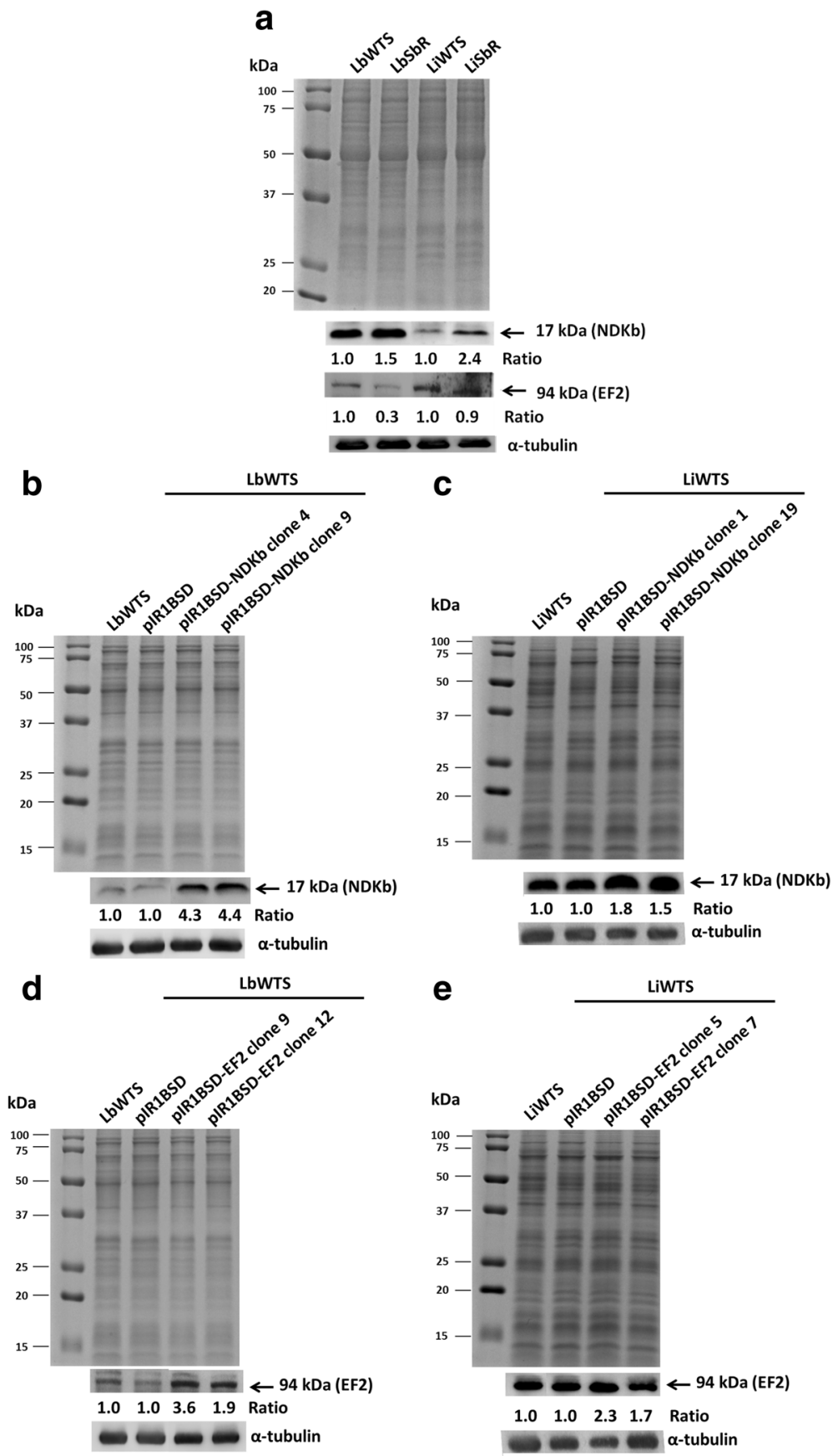

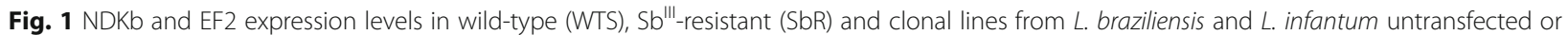
transfected with the constructs pIR1BSD (empty vector), pIR1BSD-NDKb or pIR1BSD-EF2. Total proteins $(20 \mu \mathrm{g})$ were separated by electrophoresis on 12\% SDS-polyacrylamide gel and transferred onto nitrocellulose membranes. The profiles of total proteins stained with Coomassie blue are shown. The blots were probed with rabbit polyclonal anti-NDKb (1:200) (a, b and $\mathbf{c})$ or rabbit monoclonal anti-EF2 (1:200) (a, d and e) antibodies and developed using ECL Plus kit. All membranes were incubated with the anti-a-tubulin monoclonal $(1: 15,000)$ antibody for normalization of the results. Quantification of the bands was done by densitometric analysis using the software GelAnalyzer 2010. The figure is representative of all results obtained from two different biological replicates of each sample. The values of each replicate were used to calculate the averages and for determination of the ratios presented for each protein analyzed 
protein presented the same level of expression between the LiWTS and LiSbR lines (Fig. 1a).

\section{Overexpression of $N D K b$ and EF2 genes in L. braziliensis and $L$. infantum}

Wild-type $L$. braziliensis and L. infantum lines were transfected with the constructs containing the $N D K b$ or EF2 genes (pIR1BSD-NDKb or pIR1BSD-EF2) and empty vector (pIR1BSD) to generate parasites overexpressing the enzymes NDKb and EF2. Linearization of this vector allowed integration of the constructs into the ribosomal small subunit locus [36]. To confirm the transfection, genomic DNA from the transfected clones was subjected to PCR assays using specific primers for the $B S D$ gene, which confers resistance to blasticidin. It was observed that all blasticidin-resistant clones showed a fragment of $399 \mathrm{bp}$, which corresponds to BSD marker (data not shown). These clones were subjected to Western blot assays in order to evaluate if the NDKb and EF2 enzymes were overexpressed. Our results showed that the level of NDKb protein expression was 1.5 to 4.4-fold higher in the transfected clones from $L$. braziliensis and L. infantum lines than in the nontransfected or transfected with empty vector (controls) (Fig. 1b, c). Furthermore, our analysis also demonstrated that the expression level of EF2 protein was increased 1.7 to 3.6-fold in the transfected clones from these both wild-type Leishmania lines when compared to their respective controls (Fig. 1d, e).

\section{Susceptibility of NDKb and EF2 overexpressing Leishmania spp. lines to $\mathrm{Sb}^{\text {"II }}$}

We also investigated whether the overexpression of $N D K b$ and $E F 2$ genes contributes to antimony resistance phenotype in Leishmania. For this, clonal lines from $L$. braziliensis and $L$. infantum transfected with the constructs pIR1BSD (empty vector), pIR1BSD-NDKb or pIR1BSD-EF2 and untransfected parasites were incubated with different $\mathrm{Sb}^{\mathrm{III}}$ concentrations. The $\mathrm{EC}_{50}$ was determined by counting of parasites number grown in the absence or presence of this drug. The results showed that the $\mathrm{Sb}^{\mathrm{III}} \mathrm{EC}_{50}$ of untransfected L. braziliensis line was $7 \mu \mathrm{M}$. On the other hand, the clones 4 and 9 that overexpress NDKb in this Leishmania species presented $\mathrm{EC}_{50}$ of $12 \mu \mathrm{M}$ and $15 \mu \mathrm{M}$, demonstrating an increase of 1.7 and 2.1-fold in the $\mathrm{Sb}^{\mathrm{III}}$ resistance index of these clones, respectively (Fig. 2a) (Table 1). In contrast, NDKb-overexpressing L. infantum lines did not show an increase in resistance towards $\mathrm{Sb}^{\mathrm{III}}$. The results revealed that the $\mathrm{Sb}^{\mathrm{III}} \mathrm{EC}_{50}$ of wild-type $L$. infantum line was $67 \mu \mathrm{M}$, and the NDKb overexpressing clones 1 and 19 was 81 and $73 \mu \mathrm{M}$, respectively (Fig. $2 \mathrm{~b}$ ).

Regarding EF2 gene, we observed that $\mathrm{Sb}^{\mathrm{III}} \mathrm{EC}_{50}$ of EF2-overexpressing clones 9 and 12 in L. braziliensis was $14 \mu \mathrm{M}$ and $11 \mu \mathrm{M}$, showing an increase of 2.0 and 1.6-fold in the resistance index of $\mathrm{Sb}^{\mathrm{III}}$ of these clones, respectively (Fig. 3a) (Table 1). On the other hand, EF2overexpressing L. infantum lines did not alter the $\mathrm{Sb}^{\mathrm{III}}$ susceptibility. The $\mathrm{Sb}^{\mathrm{III}} \mathrm{EC}_{50}$ of EF2-overexpressing clones 5 and 7 was $80 \mu \mathrm{M}$ and $67 \mu \mathrm{M}$, respectively (Fig. 3b).

It is important to mention that NDKb- or EF2overexpressing parasites presented similar growth curves when compared with their respective controls for both Leishmania species (data not shown). In the $\mathrm{Sb}^{\mathrm{III}}$ susceptibility assays, we observed gradual reduction in the growth of NDKb- or EF2-overexpressing parasites of $L$. braziliensis with increasing drug concentrations. In a

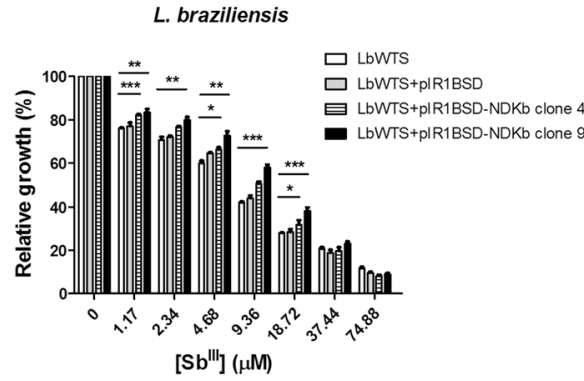

b

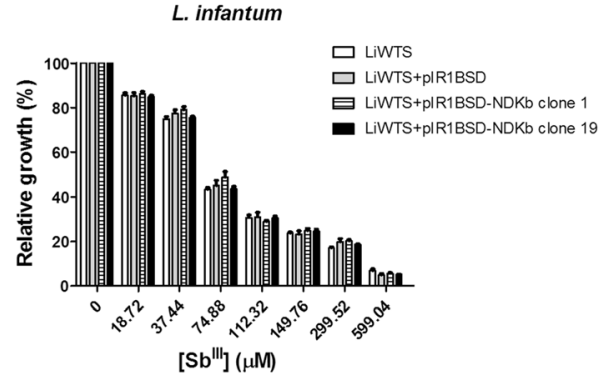

Fig. $2 \mathrm{Sb}^{\text {III }}$ susceptibility assay of clonal lines from L. braziliensis (a) and L. infantum (b) non-transfected or transfected with the constructs pIR1BSD or pIR1BSD-NDKb. Parasites were incubated in M199 medium in the absence or presence of different concentrations of Sb ${ }^{\text {III }}$ (1.17 to $599.04 \mu \mathrm{M}$ ) for $48 \mathrm{~h}$ and the percentage of relative growth was determined using a Z1 Coulter Counter. Mean values \pm standard deviations from three independent experiments in triplicate are shown. Statistical analysis was carried out using Student's $t$-test. Statistically different values are highlighted as follows: ${ }^{*} P<0.05$; ${ }^{*} P<0.01$; ${ }^{* *} P<0.001$. Pairwise comparisons (a): $\mathbf{1 . 1 7} \boldsymbol{\mu M}$ : LbWTS vs LbNDKb clone $4\left(t_{(5)}=9.47, P=0.0002\right)$; LbWTS vs LbNDKb clone $9\left(t_{(9)}=3.36, P=0.0084\right) ; 2.34 \mu \mathrm{M}$ : LbWTS vs LbNDKb clone $4\left(t_{(5)}=4.3, P=0.0077\right) ;$ LbWTS vs LbNDKb clone $9\left(t_{(8)}=3.74\right.$, $P=0.0057) ; 4.68 \mu \mathrm{M}$ : LbWTS vs LbNDKb clone $4\left(t_{(4)}=4.02, P=0.0159\right) ;$ LbWTS vs LbNDKb clone $9\left(t_{(5)}=4.99, P=0.0042\right) ; 9.36 \mu \mathrm{M}$ : LbWTS vs LbNDKb clone $4\left(t_{(6)}=8.39, P=0.0002\right) ;$ LbWTS vs LbNDKb clone $9\left(t_{(8)}=12.50, P<0.0001\right) ; 18.72 \mu M$ : LbWTS vs LbNDKb clone 4 $\left(t_{(8)}=2.88, P=0.0206\right) ;$ LbWTS vs LbNDKb clone $9\left(t_{(10)}=7.36, P<0.0001\right)$ 
a

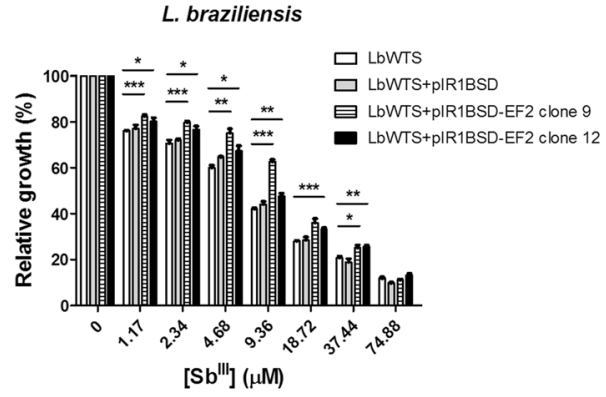

b

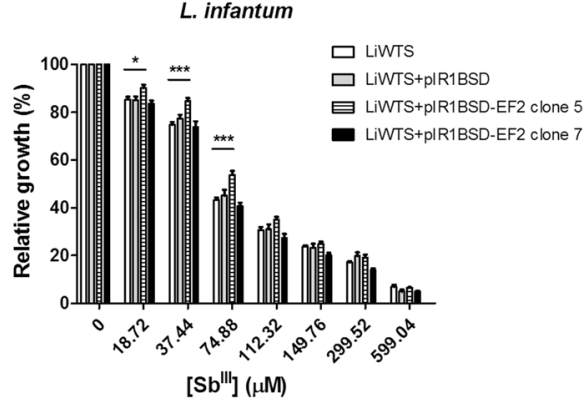

Fig. $3 \mathrm{Sb}^{\mathrm{III}}$ susceptibility assay of clonal lines from L. braziliensis (a) and L. infantum (b) non-transfected or transfected with the constructs pIR1BSD or pIR1BSD-EF2. Parasites were incubated in M199 medium in the absence or presence of different concentrations of Sb ${ }^{\text {III }}$ (1.17 to 599.04 MM) for $48 \mathrm{~h}$ and the percentage of relative growth was determined using a Z1 Coulter Counter. Mean values \pm standard deviations from three independent experiments in triplicate are shown. Statistical analysis was carried out using Student's t-test. Statistically different values are highlighted as follows: ${ }^{*} P<0.05 ;{ }^{*} P<0.01$; ${ }^{* *} P<0.001$. Pairwise comparisons (a): $1.17 \mu$ M: LbWTS vs LbEF2 clone 9 (t $\left.(9)=6.5, P=0.0001\right) ;$ LbWTS vs LbEF2 clone $12\left(\mathrm{t}_{(5)}=2.84, P=0.0361\right) ; \mathbf{2 . 3 4} \mu \mathrm{M}$ : LbWTS vs LbEF2 clone $9\left(\mathrm{t}_{(7)}=6.95, P=0.0002\right)$; LbWTS vs LbEF2 clone 12 (t $(4)=2.87, P=$

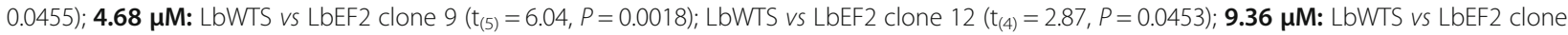
$\left.9 \mathrm{t}_{(7)}=22.18, P<0.0001\right)$; LbWTS vs LbEF2 clone $12\left(\mathrm{t}_{(8)}=4.48, P=0.0021\right) ; 18.72 \mu \mathrm{M}$ : LbWTS vs LbEF2 clone $9\left(\mathrm{t}_{(11)}=4.74, P=0.0006\right) ; \mathrm{LbWTS}$ vs. LbEF2 clone $12\left(\mathrm{t}_{(9)}=7.65, P<0.0001\right) ; \mathbf{3 7 . 4 4} \mu \mathrm{M}$ : LbWTS vs LbEF2 clone $9\left(\mathrm{t}_{(5)}=2.78, P=0.0391\right) ;$ LbWTS vs LbEF2 clone 12 (t $\left.(5)=5.1, P=0.0038\right)$. (b) $\mathbf{1 8 . 7 2} \boldsymbol{\mu M}$ : LiWTS vs LiEF2 clone 5 (t $(9)=2.67, P=0.0257) ; \mathbf{3 7 . 4 4} \boldsymbol{\mu M}$ : LiWTS vs LiEF2 clone 5 (t $(8)=6.14, P=0.0003) ; \mathbf{7 4 . 8 8} \boldsymbol{\mu M}$ : LiWTS vs LiEF2 clone $5\left(\mathrm{t}_{(9)}=4.9, P=0.0008\right)$

addition, we observed that the overexpressors of NDKb or EF2 were more resistant to $\mathrm{Sb}^{\mathrm{III}}$ until concentrations near to $\mathrm{EC}_{50}$ of these clones. In higher antimony concentrations, these parasites presented similar growth to their controls. We also observed that the vector used in our assays did not interfere in the $\mathrm{Sb}^{\mathrm{III}}$ susceptibility since no difference in $\mathrm{Sb}^{\mathrm{III}} \mathrm{EC}_{50}$ was observed between parasites untransfected and transfected with empty vector.

\section{Effect of lamivudine on the growth of wild-type and NDKb-overexpressing $L$. braziliensis lines}

Initially, the amino acid sequence of NDKb (TriTrypDB accession number LbrM.32.3210) was used to search possible drugs against this enzyme in the DrugBank (www.drugbank.ca). Search results for the submitted sequence returned three antiviral agents: tenofovir (ID DB00300), lamivudine (ID DB00709) and adefovir dipivoxil (ID DB00718). These drugs are recommended in the chemotherapy of chronic hepatitis B (HBV), and the first two are also useful to treat HIV infection. Lamivudine is a synthetic nucleoside analogue and is phosphorylated intracellularly to its active $5^{\prime}$-triphosphate metabolite (lamivudine triphosphate - LTP), which is included into viral DNA by HIV reverse transcriptase and HBV polymerase, causing the ending of DNA chain (www.drugbank.ca/drugs/DB00709). We determined the lamivudine $\mathrm{EC}_{50}$ of wild-type L. braziliensis line and parasites transfected with the constructs pIR1BSD (empty vector) and PIR1BSD-NDKb. Our data showed that the lamivudine $\mathrm{EC}_{50}$ were 2.6-fold and 2.8-fold higher for NDKb-overexpressing clones 9 and 4 (2,014 and
2,110 $\mu \mathrm{M}$, respectively) when compared to LbWTS (766 $\mu \mathrm{M})$ (Fig. 4a) (Table 1), demonstrating that these clones are more resistant to lamivudine. Competition assay was carried out to analyze the combination of lamivudine and $\mathrm{Sb}^{\mathrm{III}}$ treatment in WTS and NDKboverexpressing L. braziliensis lines. Then, the parasites were incubated simultaneously with their respective $\mathrm{EC}_{50}$ for each drug (Table 1), and after $48 \mathrm{~h}$ the relative growth of the parasites was calculated. The combined effect of both compounds reduced by $55 \%, 59.7 \%$ and $63.7 \%$, respectively, parasite numbers of LbWTS, LbNDKb clones 4 and 9, showing that the lamivudine did not increase the leishmanicidal activity of $\mathrm{Sb}^{\mathrm{III}}$ (Fig. 4b).

\section{Effect of EF2K inhibitor on the growth of wild-type and EF2-overexpressing L. braziliensis lines}

Elongation factor 2 kinase (EF2K), a calmodulindependent protein, binds numerous up-stream signals to the regulation of protein synthesis. Thus, EF2K phosphorylates EF2 and inhibits the function of this enzyme [39]. Chen et al. [40] showed that inhibition of EF2K by EF2K inhibitor decreases EF2 phosphorylation however it has little effect on proliferation in the cancer cells. Then, we tested the potential leishmanicidal effect of this inhibitor against wild-type and EF2overexpressing L. braziliensis lines. Incubation of parasites with different concentrations of EF2K inhibitor revealed that the $\mathrm{EC}_{50}$ of this drug was 1.2-fold higher for LbEF2 clone $9(211 \mu \mathrm{M})$ in comparison with LbWTS (173 $\mu \mathrm{M})$ (Fig. 5a) (Table 1). This result shows that the overexpression of EF2 enzyme protects 
a

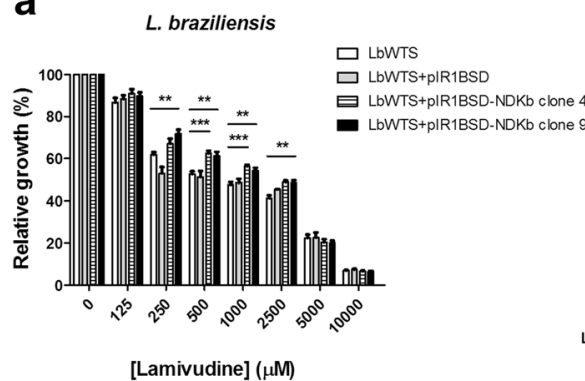

b

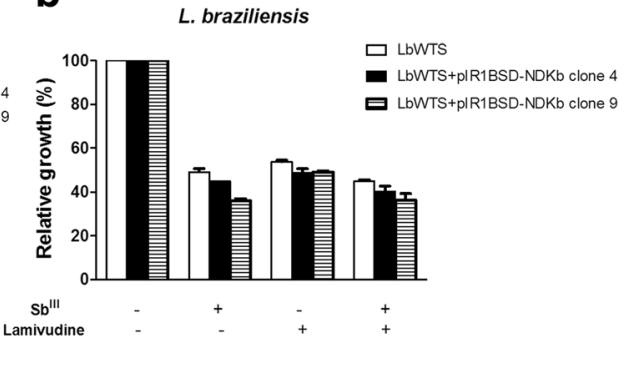

Fig. $4 \mathrm{EC}_{50}$ of lamivudine for wild-type and NDKb-overexpressing L. braziliensis lines (a) and effect of lamivudine on the growth of L. braziliensis lines upon Sb ${ }^{\text {III }}$ exposure (b). Parasites were incubated in M199 medium in the absence or presence of different concentrations of lamivudine $\left(\mathrm{C}_{8} \mathrm{H}_{11} \mathrm{~N}_{3} \mathrm{O}_{3} \mathrm{~S}\right)(125$ to $10,000 \mu \mathrm{M})$. For competition assay, cells were exposed to the $\mathrm{EC}_{50}$ of Sb"I $(7,12$ and $15 \mu \mathrm{M}$ for the LbWTS and NDKboverexpressing clones 4 and 9, respectively) and the $\mathrm{EC}_{50}$ of lamivudine (766, 2110 and $2014 \mu \mathrm{M}$ for the LbWTS and NDKb-overexpressing clones 4 and 9, respectively) independently or combined, followed by incubation for $48 \mathrm{~h}$. The percentage of relative growth was determined using a Z1 Coulter Counter. Mean values \pm standard deviations from three independent experiments in triplicate are shown. Statistical analysis was carried out using Student's t-test. Statistically different values are highlighted as follows: ${ }^{* *} P<0.01$; ${ }^{* *} P<0.001$. Pairwise comparisons (a): $250 \mu \mathrm{M}$ : LbWTS vs LbNDKb clone $9\left(\mathrm{t}_{(7)}=4.04, P=0.0049\right) ; 500 \mu \mathrm{M}$ : LbWTS vs LbNDKb clone $4\left(\mathrm{t}_{(9)}=5.27, P=0.0005\right) ;$ LbWTS vs LbNDKb clone $9\left(\mathrm{t}_{(9)}=3.74, P=0.0046\right)$; $1000 \mu$ M: LbWTS vs LbNDKb clone $4\left(\mathrm{t}_{(10)}=5.67, P=0.0002\right) ;$ LbWTS vs LbNDKb clone $9\left(\mathrm{t}_{(10)}=3.52, P=0.0055\right) ; 2500 \mu \mathrm{M}$ : LbWTS vs LbNDKb clone 4 $\left(\mathrm{t}_{(8)}=5.03, P=0.0010\right)$; LbWTS vs LbNDKb clone $9\left(\mathrm{t}_{(8)}=3.91, P=0.0045\right)$

slightly Leishmania from lethal action of EF2K inhibitor. In addition, we evaluated the effect of EF2K inhibitor on the growth of L. braziliensis lines upon $\mathrm{Sb}^{\mathrm{III}}$ exposure. Surprisingly, the combined treatment $\mathrm{Sb}^{\mathrm{III}}$ with EF2K inhibitor enhanced the leishmanicidal activity against both $L$. braziliensis lines compared to those incubated with $\mathrm{Sb}^{\mathrm{III}}$ or EF2K inhibitor alone (Fig. 5b). Additionally, this increased $\mathrm{Sb}^{\mathrm{III}}$ susceptibility was higher in the EF2-overexpressing L. braziliensis clone 9 (88\% growth inhibition) than in the wild-type L. braziliensis line $(77.7 \%$ growth inhibition), suggesting a possible involvement of EF2 in this activity.

\section{Susceptibility of NDKb-overexpressing $L$. braziliensis lines} to $\mathrm{H}_{2} \mathrm{O}_{2}$

L. braziliensis clonal lines overexpressing $N D K b$ gene were submitted to susceptibility assays with $\mathrm{H}_{2} \mathrm{O}_{2}$ to evaluate the tolerance to oxidative stress generated by different concentrations of this compound. Our results demonstrated that LbWTS line showed an $\mathrm{H}_{2} \mathrm{O}_{2} \mathrm{EC}_{50}$ of $213 \mu \mathrm{M}$, and the LbNDKb clones 4 and 9 displayed the same value of $\mathrm{EC}_{50}$ for $\mathrm{H}_{2} \mathrm{O}_{2}$, which was equal to $207 \mu M$ (Table 1). These data suggest that NDKb enzyme is not directly involved in the defense against oxidative stress in L. braziliensis. a

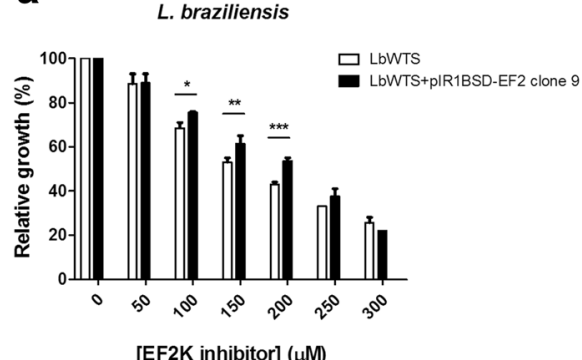

b

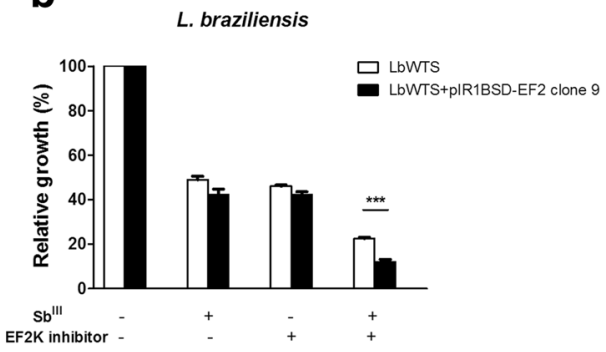

Fig. $5 \mathrm{EC}_{50}$ of elongation factor 2 kinase (EF2K) inhibitor for wild-type and EF2-overexpressing L. braziliensis lines (a) and effect of EF2K inhibitor on the growth of L. braziliensis lines upon Sb $b^{\prime \prime \prime}$ exposure (b). Parasites were incubated in M199 medium in the absence or presence of different concentrations of EF2K inhibitor $\left(\mathrm{C}_{13} \mathrm{H}_{15} \mathrm{~N}_{5} \mathrm{O}_{3}\right)(50$ to $300 \mu \mathrm{M})$. For competition assay, cells were exposed to the EC 50 of $\mathrm{Sb}^{\text {III }}$ (7 and $14 \mu \mathrm{M}$ for the LbWTS and EF2-overexpressing clone 9, respectively) and the EC 50 of EF2K inhibitor (173 and $211 \mu \mathrm{M}$ for the LbWTS and EF2-overexpressing clone 9 , respectively) independently or combined, followed by incubation for $48 \mathrm{~h}$. The percentage of relative growth was determined using a Z1 Coulter Counter. Mean values \pm standard deviations from three independent experiments in triplicate are shown. Statistical analysis was carried out using Student's $t$-test. Statistically different values are highlighted as follows: ${ }^{*} P<0.05 ;{ }^{* *} P<0.01 ;{ }^{* * *} P<0.001$. Pairwise comparisons (a): $100 \mu \mathrm{M}: \mathrm{t}_{(6)}=3.52, P=0.0126 ; \mathbf{1 5 0} \boldsymbol{\mu M}: \mathrm{t}_{(6)}=3.94, P=0.0076 ; \mathbf{2 0 0} \boldsymbol{\mu M}: \mathrm{t}_{(6)}=8.83, P=0.0001 .(\mathbf{b}) \mathbf{S b}^{\text {III }}+\mathbf{E F} \mathbf{K}$ inhibitor: $\mathrm{t}_{(4)}=11.72, P=0.0003$ 


\section{Discussion}

In the absence of effective vaccine against leishmaniasis, the only way to treat and control all forms of the disease is through the use of chemotherapy. Pentavalent antimonials are considered one of the main options of treatment; however these drugs have several toxic side effects and high resistance rates. Drug resistance in leishmaniasis has a multifactorial origin, involving different factors related to host, parasite and drug [41]. Thus, the comprehension of resistance molecular mechanisms in Leishmania spp. is essential to identify novel drug targets to prevent or reverse such mechanisms. Recently, our phosphoproteomic study identified the proteins nucleoside diphosphate kinase $\mathrm{b}(\mathrm{NDKb})$ and elongation factor 2 (EF2) differently modulated in antimonyresistant L. braziliensis samples [34]. The results presented in this study corroborate with these data once we observed that the NDKb and EF2 proteins were more and less expressed, respectively, in the LbSbR line than the LbWTS pair. Literature data to date provide no functional analysis of these proteins in Leishmania. Therefore, overexpression of $N D K b$ and EF2 genes in New World L. braziliensis and L. infantum species were performed here to investigate the contribution of these genes in antimony resistance phenotype.

$\mathrm{NDKb}$ is a member of the NDK family which is implicated in multiple cellular processes [42]. NDKs have a key role in the purine metabolism in pathogenic parasites such as Leishmania spp. and Trypanosoma spp., which makes these enzymes potential targets for the development of new strategies for trypanosomiasis treatment [43]. NDK, which corresponds to Nm23 gene family in the human genome, can be considered a tumor metastasis suppressor [44, 45]. Furthermore, it has differential abilities to modulate tumorigenesis [46]. Here we observed that NDKb protein is more expressed in $\mathrm{Sb}^{\mathrm{III}}$-resistant $L$. braziliensis and $L$. infantum lines than in the corresponding wild-type lines. Interestingly, proteomic analysis showed that the NDK enzyme was more abundant in a benznidazole-resistant Trypanosoma cruzi population [47]. In our study, transfection of the $N D K b$ gene in wild-type L. braziliensis and L. infantum lines led to increase of NDKb protein levels in the transfected clones when compared to their parental counterparts, as demonstrated by Western blot results. Functional assays showed that L. braziliensis clonal lines overexpressing this enzyme are less susceptible to $\mathrm{Sb}^{\mathrm{III}}$ in relation to untransfected parasites. Nevertheless, no difference was observed in the susceptibility to antimony between the wild-type and NDKb-overexpressing $L$. infantum lines, demonstrating that this gene does not alter the $\mathrm{Sb}^{\mathrm{III}}$-resistance phenotype in this species.

In our search for possible inhibitors of NDKb enzyme, we found a drug known as lamivudine that is used in the chemotherapy of HIV and HBV diseases. According to DrugBank (www.drugbank.ca/drugs/DB00709), lamivudine is phosphorylated to active metabolites that compete for integration into DNA of the virus. These metabolites inhibit the HIV reverse transcriptase enzyme competitively and function as a terminator of DNA chain synthesis. The absence of a $3^{\prime}-\mathrm{OH}$ group in the incorporated nucleoside analogue stops the formation of the $5^{\prime}$ to $3^{\prime}$ phosphodiester linkage required for DNA chain elongation, and thereby, the growth of viral DNA is finished. Our study showed that overexpression of the NDKb enzyme confers resistance to lamivudine. The results propose that the parasites express the active form of this enzyme and that lamivudine probably prevents the transfer of $\gamma$-phosphoryl groups from NTP to NDP in the parasite. In addition, our results revealed that the combination lamivudine and $\mathrm{Sb}^{\mathrm{III}}$ does not alter the leishmanicidal effect, suggesting that this combination is not a good strategy to be used in the leishmaniasis chemotherapy.

Attenuation of reactive oxygen species (ROS) production is an additional function proposed for secreted NDKs by pathogenic microorganisms [48]. Our results revealed that overexpression of $\mathrm{NDKb}$ enzyme did not alter the susceptibility of parasites to $\mathrm{H}_{2} \mathrm{O}_{2}$. These findings suggest that NDKb enzyme is not directly involved in the defense against oxidative stress in L. braziliensis.

Molecular mechanisms that regulate protein synthesis are essential for various biological phenomena. Protein translation is a process regulated at the initiation and elongation levels. There are diverse factors responsible for the regulation at translation elongation, but EF2 along EF1A are one of the most important enzymes which conduct the elongation cycle of protein synthesis in eukaryotic cells [49]. Our previous phosphoproteomic study demonstrated that EF2 protein presented lower abundance in $\mathrm{Sb}^{\mathrm{III}}$-resistant L. braziliensis samples [34], suggesting that this protein was dephosphorylated (active state) to regulate the elongation of essential proteins which are crucial to maintain the antimony resistance phenotype. Other studies also found EF2 contributing to this phenotype in different Leishmania species. EF2 was found with higher abundance in $\mathrm{Sb}^{\mathrm{V}}$-resistant $L$. donovani isolates [50], $\mathrm{Sb}^{\mathrm{III}}$-resistant $L$. panamensis and $L$. infantum lines [33, 51]. However, according our previous results this protein probably might be dephosphorylated in these antimony-resistant parasites. Thus, these studies demonstrate that there are differences among Leishmania species, which can result in variations in the degree of phosphorylation or expression of the EF2 protein.

In this work, we transfected the EF2 gene to analyze if the overexpression of this enzyme contributes for $\mathrm{Sb}^{\mathrm{III}}$ resistance in Leishmania species. Western blot assays 
revealed that the expression level of this protein was higher in $L$. braziliensis and L. infantum lines overexpressing EF2 in comparison with their respective wildtype counterparts. Experiments of susceptibility to antimony showed that both L. braziliensis clones transfected with EF2 gene were more resistant to $\mathrm{Sb}^{\mathrm{III}}$ than the controls (wild-type and empty vector). On the other hand, the EF2-overexpressing L. infantum lines did not present difference in the susceptibility to $\mathrm{Sb}^{\mathrm{III}}$ when compared to its parental line, showing that this gene is not relevant to $\mathrm{Sb}^{\mathrm{III}}$ resistance in this Leishmania species. Overexpression of EF2 was observed in patients with lung adenocarcinoma [52] and related with reduced cell death after exposure to cumene hydroperoxide [53]. Kushawaha et al. [54] demonstrated that EF2, a Th1 stimulatory protein of $L$. donovani, produces strong IFN- $\gamma$ and IL-12 response in cured Leishmania-infected patients/hamsters and confers considerable protection against experimental visceral leishmaniasis.

EF2 can be regulated through inhibitory phosphorylation at threonine 56 (T56) by EF2K [55]. Phosphorylation on T56 inactivates EF2 and it is the unique known regular EF2 functional alteration. Differently, EF2K suffers vast regulatory phosphorylations that permit distinct pathways to impact elongation [32]. Our results showed that EF2overexpressing clone showed slight resistance to the EF2K inhibitor in comparison with the wild-type line. Surprisingly, this inhibitor increased the antileishmanial effect of $\mathrm{Sb}^{\mathrm{II}}$, especially against EF2-overexpressing parasites. Chen et al. [40] showed that the concentrations of this inhibitor that effectively inhibited EF2 phosphorylation did not produce significant inhibition of cancer cell proliferation.

Our results demonstrated that both NDKb and EF2 proteins of Leishmania presented approximately $60 \%$ of identity with the mammal proteins, indicating a good degree of conservation between these proteins. In this way, further studies are needed to investigate the cytotoxicity of lamivudine and EF2K inhibitor against mammalian cells.

\section{Conclusions}

Our findings represent the first study of $N D K b$ and $E F 2$ genes overexpression in Leishmania species, demonstrating that these proteins are implicated in $\mathrm{Sb}^{\mathrm{III}}$ resistance phenotype in L. braziliensis. Susceptibility assays showed that $\mathrm{NDKb}$-overexpressing lines were more resistant to lamivudine, and EF2-overexpressing clone was moderately more resistant to EF2K inhibitor. In addition, our results suggest that the combined treatment EF2K inhibitor with $\mathrm{Sb}^{\mathrm{III}}$ might be a good strategy to increase antileishmanial effect. Therefore, our data provided in this report bring new knowledges about resistance to $\mathrm{Sb}^{\mathrm{III}}$ in Leishmania which can contribute to develop new strategies for leishmaniasis chemotherapy.

\section{Abbreviations}

EF2: Elongation factor 2; EF2K: Elongation factor 2 kinase; Lb: Leishmania (V.) braziliensis; Li: Leishmania (L.) infantum; NDKb: Nucleoside diphosphate kinase

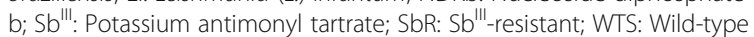
susceptible

\section{Acknowledgements}

We thank Dr. Stephen Beverley (Washington University, USA) for kindly provided the pIR1BSD expression vector, Dr. Juliana Medeiros and Dr. Ana Cláudia Tavares (Farmanguinhos/FIOCRUZ-RJ, Brazil) for kindly provided the lamivudine, and Mariana Xavier for help in automated cell counting during the susceptibility assays to Sb"I. The authors wish to thank the Program for Technological Development in Tools for Health-PDTIS-FIOCRUZ for use of its facilities.

\section{Funding}

This study received financial support from the following agencies: Conselho Nacional de Desenvolvimento Científico e Tecnológico (CNPq/Universal 475782/2012-7), Fundação de Amparo à Pesquisa do Estado de Minas Gerais (FAPEMIG - CBB-PPM00196/13 and 00610/15), UNICEF/UNDP/World Bank/ WHO (TDR), P3D-Programa de descoberta e desenvolvimento de drogas (PROEP/CNPq/FIOCRUZ 401988/2012-0). S. M. F. Murta is research fellows supported by CNPq (National Council for the Development of Research of Brazil) and D. S. Moreira by CNPq (140435/2013-1).

The funders had no role in the study design, data collection and analysis, decision to publish, or preparation of the manuscript.

Availability of data and materials

All data generated or analyzed during this study are included in the article.

Authors' contributions

Conceived, designed and performed the experiments, analyzed the data and helped to draft the manuscript: DSM and SMFM. Both authors read and approved the final manuscript.

Competing interests

The authors declare that they have no competing interests.

Consent for publication

Not applicable.

Ethics approval and consent to participate

Not applicable.

Received: 12 September 2016 Accepted: 5 December 2016 Published online: 13 December 2016

\section{References}

1. World Health Organization. Leishmaniasis. http://www.who.int/mediacentre/ factsheets/fs375/en/. Accessed 07 Sep 2016

2. Alvar J, Vélez ID, Bern C, Herrero M, Desjeux P, Cano J, Jannin J, den Boer M, W.H.O. Leishmaniasis Control Team. Leishmaniasis worldwide and global estimates of its incidence. PLoS One. 2012;7:e35671.

3. Murray HW, Berman JD, Davies CR, Saravia NG. Advances in leishmaniasis. Lancet. 2005;366:1561-77.

4. Marzochi MC, Marzochi KB. Tegumentary and visceral leishmaniases in Brazil: emerging anthropozoonosis and possibilities for their control. Cad Saude Publica. 1994;2:359-75

5. Ashutosh G, Sundar S, Goyal N. Molecular mechanisms of antimony resistance in Leishmania. J Med Microbiol. 2007;56:143-53.

6. Alvar J, Croft S, Olliaro P. Chemotherapy in the treatment and control of leishmaniasis. Adv Parasitol. 2006:61:223-74.

7. Frézard F, Demicheli C, Ferreira CS, Costa MAP. Glutathione-induced conversion of pentavalent antimony to trivalent antimony in meglumine antimoniate. Antimicrob Agents Chemother. 2001;45:913-16.

8. Berman JD, Gallalee JV, Best JM. Sodium stibogluconate (Pentostam) inhibition of glucose catabolism via the glycolytic pathway and fatty acid beta-oxidation in Leishmania mexicana amastigotes. Biochem Pharm. 1987; 36:197-201 
9. Wyllie S, Cunningham ML, Fairlamb AH. Dual action of antimonial drugs on thiol redox metabolism in the human pathogen Leishmania donovani. J Biol Chem. 2004;279:39925-32.

10. Sereno D, Holzmuller P, Mangot I, Cuny G, Ouaissi A, Lemesre JL. Antimonial-mediated DNA fragmentation in Leishmania infantum amastigotes. Antimicrob Agents Chemother. 2001:45:2064-69.

11. Sudhandiran G, Shaha C. Antimonial-induced increase in intracellular Ca ${ }^{2+}$ through non-selective cation channels in the host and the parasite is responsible for apoptosis of intracellular Leishmania donovani amastigotes. J Biol Chem. 2003;278:25120-32.

12. Thakur CP, Dedet JP, Narain S, Pratlong F. Leishmania species, drug unresponsiveness and visceral leishmaniasis in Bihar, India. Trans R Soc Trop Med Hyg. 2001;95:187-9.

13. Denton H, McGregor JC, Coombs GH. Reduction of antileishmanial pentavalent antimonial drugs by a parasite-specific thiol-dependent reductase, TDR1. Biochem J. 2004;381:405-12.

14. Zhou Y, Messier N, Ouellette M, Rosen BP, Mukhopadhyay R. Leishmania major LmACR2 is a pentavalent antimony reductase that confers sensitivity to the drug Pentostam. J Biol Chem. 2004;279:37445-51.

15. Gourbal B, Sonuc N, Bhattacharjee H, Légaré D, Sundar S, Ouellette M, et al. Drug uptake and modulation of drug resistance in Leishmania by an aquaglyceroporin. J Biol Chem. 2004;279:31010-7.

16. Marquis N, Gourbal B, Rosen BP, Mukhopadhyay R, Ouellette M. Modulation in aquaglyceroporin AQP1 gene transcript levels in drug-resistant Leishmania. Mol Microbiol. 2005;57:1690-9.

17. Haimeur A, Brochu C, Genest P, Papadopoulou B, Ouellette M. Amplification of the $A B C$ transporter gene PGPA and increased trypanothione levels in potassium antimonyl tartrate $\left(\mathrm{Sb}^{\mathrm{III}}\right)$ resistant Leishmania tarentolae. Mol Biochem Parasitol. 2000;108:131-5.

18. Decuypere S, Rijal S, Yardley V, De Doncker S, Laurent T, Khanal B, et al. Gene expression analysis of the mechanism of natural $\mathrm{Sb}(\mathrm{V})$ resistance in Leishmania donovani isolates from Nepal. Antimicrob Agents Chemother. 2005;49:4616-21.

19. Mittal MK, Rai S, Ashutosh R, Gupta S, Sundar S, Goyal N. Characterization of natural antimony resistance in Leishmania donovani isolates. Am J Trop Med Hyg. 2007;76:681-8.

20. Mandal G, Wyllie S, Singh N, Sundar S, Fairlamb AH, Chatterjee M. Increased levels of thiols protect antimony unresponsive Leishmania donovani field isolates against reactive oxygen species generated by trivalent antimony. Parasitology. 2007;134:1679-87.

21. El Fadili K, Messier N, Leprohon P, Roy G, Guimond C, Trudel N, et al. Role of the $\mathrm{ABC}$ transporter MRPA (PGPA) in antimony resistance in Leishmania infantum axenic and intracellular amastigotes. Antimicrob Agents Chemother. 2005:49:1988-93.

22. Légaré $D$, Richard D, Mukhopadhyay R, Stierhof YD, Rosen BP, Haimeu $A$, et al. The Leishmania ATP-binding cassette protein PGPA is an intracellular metal-thiol transporter ATPase. J Biol Chem. 2001;276: 26301-7.

23. Parks Jr RE, Brown PR, Cheng YC, Agarwal KC, Kong CM, Agarwal RP, Parks CC. Purine metabolism in primitive erythrocytes. Comp Biochem Physiol B. 1973;45:355-64.

24. Lascu I, Gonin P. The catalytic mechanism of nucleoside diphosphate kinases. J Bioenerg Biomembr. 2000;32:237-46.

25. Paul ML, Kaur A, Geete A, Sobhia ME. Essential gene identification and drug target prioritization in Leishmania species. Mol Biosyst. 2014;10: 1184-95.

26. Chakrabarty AM. Nucleoside diphosphate kinase: role in bacterial growth, virulence, cell signaling and polysaccharide synthesis. Mol Microbiol. 1998; 28:875-82.

27. Postel EH. Multiple biochemical activities of NM23/NDP kinase in gene regulation. J Bioenerg Biomembr. 2003;35:31-40.

28. Landfear SM, UIIman B, Carter NS, Sanchez MA. Nucleoside and nucleobase transporters in parasitic protozoa. Eukaryot Cell. 2004;3:245-54.

29. Carter NS, Rager N, Ullman B. Purine and pyrimidine transport and metabolism. In: Marr JJ, Nilsen T, Komunieck R, editors. Molecular and Medical Parasitology. London: Academic; 2003. p. 197-223.

30. Kolli BK, Kostal J, Zaborina O, Chakrabarty AM, Chang KP. Leishmaniareleased nucleoside diphosphate kinase prevents ATP-mediated cytolysis of macrophages. Mol Biochem Parasitol. 2008;158:163-75.

31. Rennie MJ. Why muscle stops building when it's working. J Physiol. 2005;569:3.
32. Hizli AA, Chi Y, Swanger J, Carter JH, Liao Y, Welcker M, Ryazanov AG, Clurman BE. Phosphorylation of eukaryotic elongation factor 2 (eEF2) by cyclin A-cyclin-dependent kinase 2 regulates its inhibition by eEF2 kinase. Mol Cell Biol. 2013;33:596-604.

33. Walker J, Gongora R, Vasquez JJ, Drummelsmith J, Burchmore R, Roy G, et al. Discovery of factors linked to antimony resistance in Leishmania panamensis through differential proteome analysis. Mol Biochem Parasitol. 2012;183:166-76.

34. Moreira DS, Pescher P, Laurent C, Lenormand P, Späth GF, Murta SM. Phosphoproteomic analysis of wild-type and antimony-resistant Leishmania braziliensis lines by 2D-DIGE technology. Proteomics. 2015;17:2999-3019.

35. Liarte DB, Murta SMF. Selection and phenotype characterization of potassium antimony tartrate-resistant populations of four New World Leishmania species. Parasitol Res. 2010;107:205-12.

36. Robinson KA, Beverley SM. Improvements in transfection efficiency and tests of RNA interference (RNAi) approaches in the protozoan parasite Leishmania. Mol Biochem Parasitol. 2003;128:217-28.

37. Gamarro F, Chiquero MJ, Amador MV, Légaré D, Ouellette M, Castanys S. Pglycoprotein overexpression in methotrexate-resistant Leishmania tropica. Biochem Pharmacol. 1994;47:1939-47.

38. Huber W, Koella JC. A comparison of three methods of estimating EC50 in studies of drug resistance of malaria parasites. Acta Trop. 1993;55:257-61.

39. Ryazanov AG, Spirin AS. Phosphorylation of elongation factor 2: a key mechanism regulating gene expression in vertebrates. New Biol. 1990;2: 843-50.

40. Chen Z, Gopalakrishnan SM, Bui MH, Soni NB, Warrior U, Johnson EF, et al. 1-Benzyl-3-cetyl-2-methylimidazolium iodide (NH125) induces phosphorylation of eukaryotic elongation factor-2 (eEF2): a cautionary note on the anticancer mechanism of an eEF2 kinase inhibitor. J Biol Chem. 2011:286:43951-8.

41. Vanaerschot M, Dumetz F, Roy S, Ponte-Sucre A, Arevalo J, Dujardin JC. Treatment failure in leishmaniasis: drug-resistance or another (epi-) phenotype? Expert Rev Anti Infect Ther. 2014;12:937-46.

42. Lacombe ML, Milon L, Munier A, Mehus JG, Lambeth DO. The human Nm23/nucleoside diphosphate kinases. J Bioenerg Biomembr. 2000;32:247-58

43. Marr JJ. Purine analogs as chemotherapeutic agents in leishmaniasis and American trypanosomiasis. J Lab Clin Med. 1991;118:111-9.

44. Rosengard AM, Krutzsch HC, Shearn A, Biggs JR, Barker E, Margulies IM, et al. Reduced Nm23/Awd protein in tumour metastasis and aberrant Drosophila development. Nature. 1989;342:177-80.

45. Nakayama T, Ohtsuru A, Nakao K, Shima M, Nakata K, Watanabe K, et al. Expression in human hepatocellular carcinoma of nucleoside diphosphate kinase, a homologue of the nm23gene product. J Natl Cancer Inst. 1992;84: 1349-54.

46. Tong $Y$, Yung LY, Wong $Y$ H. Metastasis suppressors $\mathrm{Nm} 23 \mathrm{H} 1$ and $\mathrm{Nm} 23 \mathrm{H} 2$ differentially regulate neoplastic transformation and tumorigenesis. Cancer Lett. 2015;361:207-17.

47. Andrade HM, Murta SM, Chapeaurouge A, Perales J, Nirdé P, Romanha AJ. Proteomic analysis of Trypanosoma cruzi resistance to Benznidazole. J Proteome Res. 2008;7:2357-67.

48. Spooner R, Yilmaz Ö. Nucleoside-diphosphate-kinase: a pleiotropic effector in microbial colonization under interdisciplinary characterization. Microbes Infect. 2012;14:228-37.

49. Kaul G, Pattan G, Rafeequi T. Eukaryotic elongation factor-2 (eEF2): its regulation and peptide chain elongation. Cell Biochem Funct. 2011;29:227-34

50. Biyani N, Singh AK, Mandal S, Chawla B, Madhubala R. Differential expression of proteins in antimony-susceptible and -resistant isolates of Leishmania donovani. Mol Biochem Parasitol. 2011;179:91-9.

51. Matrangolo FS, Liarte DB, Andrade LC, de Melo MF, Andrade JM, Ferreira RF, et al. Comparative proteomic analysis of antimony-resistant and -susceptible Leishmania braziliensis and Leishmania infantum chagasi lines. Mol Biochem Parasitol. 2013;190:63-75.

52. Chen CY, Fang HY, Chiou SH, Yi SE, Huang CY, Chiang SF, et al. Sumoylation of eukaryotic elongation factor 2 is vital for protein stability and anti-apoptotic activity in lung adenocarcinoma cells. Cancer Sci. 2011;102:1582-9.

53. Argüelles S, Camandola S, Hutchison ER, Cutler RG, Ayala A, Mattson MP. Molecular control of the amount, subcellular location, and activity state of translation elongation factor 2 in neurons experiencing stress. Free Radic Biol Med. 2013;61:61-71 
54. Kushawaha PK, Gupta R, Sundar S, Sahasrabuddhe AA, Dube A. Elongation factor-2, a Th1 stimulatory protein of Leishmania donovani, generates strong IFN- $\gamma$ and IL-12 response in cured Leishmania-infected patients/hamsters and protects hamsters against Leishmania challenge. J Immunol. 2011;187:6417-27.

55. Ryazanov AG, Davydova EK. Mechanism of elongation factor 2 (EF-2) inactivation upon phosphorylation. Phosphorylated EF-2 is unable to catalyze translocation. FEBS Lett. 1989;251:187-90.

Submit your next manuscript to BioMed Central and we will help you at every step:

- We accept pre-submission inquiries

- Our selector tool helps you to find the most relevant journal

- We provide round the clock customer support

- Convenient online submission

- Thorough peer review

- Inclusion in PubMed and all major indexing services

- Maximum visibility for your research

Submit your manuscript at www.biomedcentral.com/submit 